\title{
Metaheuristic Optimization Algorithm of MPPT Controller for PV system application
}

\author{
Mohamed Yaich $^{1}$, Youssef Dhieb $^{1 *}$, Mounir Bouzguenda ${ }^{2}$, and Moez Ghariani ${ }^{1}$ \\ ${ }^{1}$ ESSE, University of Sfax, ENE'TCOM, B.P 1163, 3018 Sfax, Tunisia. \\ ${ }^{2}$ King Faisal University, College of Engineering Al Hasa, Saudi Arabia.
}

\begin{abstract}
The Maximum Power Point Tracking controller (MPPT) is a key element in Photovoltaic systems (PV) since it allows maintaining the PV operating point at its maximum under different temperatures and sunlight irradiations. Metaheuristic algorithms such as the ant colony optimization (ACO) are adopted and have shown their superiority to many other techniques. The perturb and observe (P\&O) algorithm is a simple and efficient technique, and is one of the most commonly employed MPPT schemes for PV power generation systems. Which executed by manipulating direct duty ratio of the boost converter. $\mathrm{P} \& \mathrm{O}$ method miserably fails to recognize various MPPT controllers. This paper proposes ACO technique to solve real-life problems.
\end{abstract}

\section{Introduction}

As technology advances, scientists and researchers are finding new alternative efficient ways to generate electricity in our homes, offices, schools, hospitals and vehicles. Solar energy continues to be the one that stands out amongst all renewable energy resources. Solar energy is derived from the sun, as the sun releases photons; these photovoltaic (PV) cells then directly convert sunlight into electricity, but as the solar irradiation and temperature are fluctuating in nature, as a result, it reduces the PV panel efficiency. The main drawbacks of the PV system are its highly intermittent nature, lower conversion efficiency, lower rating, high implementation cost, and maintenances issues. PV panels also get affected due to partial shading because of clouds, tree branches, birds, etc [2].

Moreover, the current-voltage (I-V) and powervoltage $(\mathrm{P}-\mathrm{V})$ characteristics of the solar cell are nonlinear curves, and change depending on irradiation and temperature. In general, there is a unique point on the (I-V) or (P-V) curve, called the Maximum Power Point (MPP), at witch the entire PV system (array, inverter, etc.) operates with maximum efficiency and produces its maximum output power. Varying insolation changes all the parameters ( PMAX, VMAX, IMAX, VOC, ISC) of the solar cell shown in characteristics curves of the PV cell in Fig.1[1]. The location of the MPP is not known, but can be located, either through mathematical calculation models or by search algorithms. The of Maximum Power Point Tracking (MPPT) controller is to ensure that at any environmental condition, the maximum power is extracted from the PV modules by matching its I-V operating point with the corresponding power converter.
Generally, a PV array operates in conjunction with dcdc power converter, whose duty cycle is adjusted to appropriately track the MPP of the array.

However because of the non-linear I-V characteristics of the PV sources and the consequence of the varying environmental conditions, tracking of correct maximum power point (MPP) can sometimes be a challenging task. During the last few decades, such controllers are becoming an essential part of the PV systems and numerous research works are being done from research and/or industry in order to increase the efficiency of these systems. Despite the fact that these MPPT controllers are designed for the same objective, they differ significantly in terms of complexity, flexibility, number of required sensors, robustness, convergence speed, hardware implementation, effectiveness and the techniques used [3].

Namely, MPPT controllers can be implemented using conventional methods (CM) and/ or soft computing methods (SCM). In the class of $\mathrm{CM}$, we mention the well-established and widely used Perturb and Observe, the incremental conductance and the Hill Climbing MPPT controllers. These CM are simple, easy to implement and capable of tracking the MPP efficiently in normal conditions.

However, this method has a drawback related to the continuous oscillations that occur around the MPP resulting in considerable loss of power during steady state. The principle of the proposed technique will be developed to overcome these problems. In recent years, MPPT based on soft computing methods (SCM) have attracted huge interest from research communities, due to their ability to solve the problem of the nonlinear I-V or P-V functions.

\footnotetext{
*Corresponding author: youssef.dhieb@enetcom.u-sfax.tn
} 
Among these methods, we mention the latest proposed methods as follow: Ant Colony Algorithm (ACO), Particle Swarm Optimization (PSO), Artificial Bee Colony (ABC), Cuckoo Search Algorithm (CSA), Firefly Algorithm (FA) , Bat Algorithm (BA), Evolutionary Algorithms, Flower Pollination Algorithm (FPA), Glowworm Swarm Optimization (GSO), Gray Wolf Optimization (GWO), Teaching Learning Based Optimization (TLBO), Generalized Pattern Search (GPS), Bacteria Foraging (BF), Chaos Optimization Search (COS), and Shuffled Frog Leaping Algorithm (SFLA) .

Particularly, the application of the ACO algorithm in the field of PV systems caught our attention, for the following reasons: first, because of the principle and the advantage of the ACO algorithm itself; and second, because there are only few propositions related to the use of the ACO technique in the field of PV systems control scheme.

The paper is organized as follows. In section 2, we give a general presentation of the PV system and the characteristics of a PV array. The model of boost converter is established in section 3. Section 4 presents the conventional algorithm perturb and observe ( $\mathrm{P} \& \mathrm{O})$ to validate the maximum power point tracking (MPPT) applied to the studied convert under variations of climatic conditions. To obtain the optimal output power, ACO algorithm used in section 5. Resulting performances and comparative study of the presented system have been studied via simulations using MATLAB/Simulink software in section 6.Finally; conclusions are made in section 7.

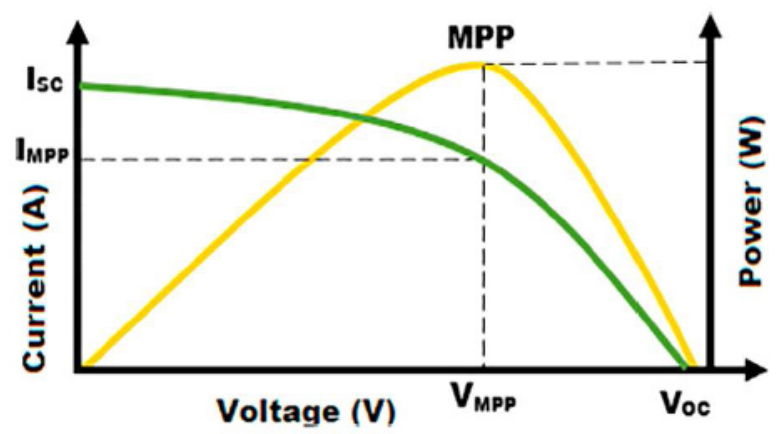

Fig. 1. I-V and P-V Characteristics of Solar PV cell

\section{PRESENTATION OF PHOTOVOLTAIC SYSTEM}

The main architecture of the proposed PV system is depicted in Fig.2. It consist of a PV module for energy extraction from the sun, a boost converter, a load and MPPT controller.

The PV array is constructed by $\mathrm{Np}$ strings in parallel; each string is formed by Ns modules in series. Generally, one module is built with some cells coupled in series. A PV cell can deliver just a little quantity of power, why an assemblage of many cells is necessary for feeding various PV applications. PV cell produces electricity from light energy using the photovoltaic effect, which is an optoelectronic phenomenon. The material most used for solar cells is the crystalline silicon, which can be extracted from the sand or the rock. The principal manufacturing technologies of modules PV are monocrystalline, polycrystalline or amorphous.

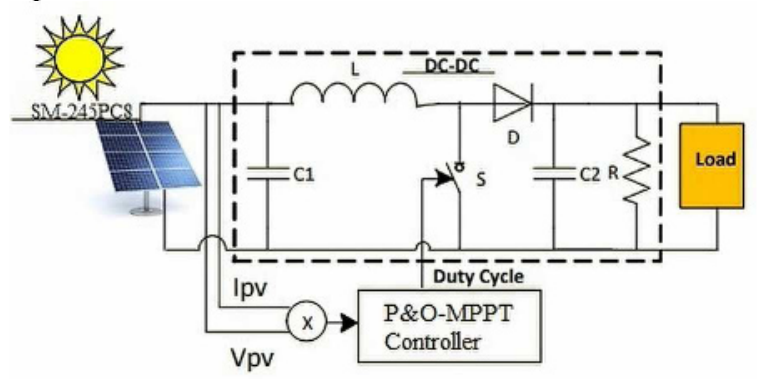

Fig. 2. Photovoltaic System Architecture

Many works in literature speak very well about the modeling and characteristics of solar module. The PV cell is usually represented by single or double exponential models, but the last is more difficult to solve. For simplicity, the single exponential model (aka one diode model) shown in Fig.3 is utilized in this paper which provides a good compromise between accuracy and model complexity. The basic equation that describes the I-V characteristic of the model is given by [2]:

$$
I=I_{P V}-I_{0}\left\lceil\exp \left\lceil\frac{V+I R_{S}}{a V_{T}}\right\rceil-1\right\rceil-\frac{V+I R_{S}}{R_{p}}
$$

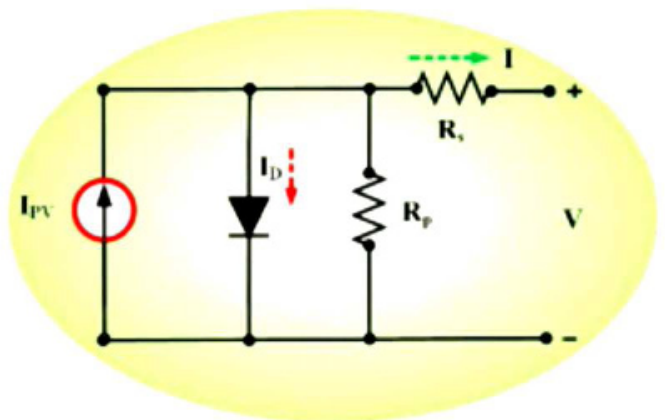

Fig. 3. Circuit for the modelling of a single diode PV cell.

Where VT is the PV array thermal voltage $=\mathrm{kT} / \mathrm{q}$. IPV represents the photocurrent, I0 represents reverse saturation current, and RS and RP represent the series and parallel resistance respectively, $\mathrm{a}$ is the diode ideality factor, $\mathrm{q}$ is the charge of the electron i.e., 1.6 *10-10 C, $\mathrm{k}$ represents Boltzmann's constant $(1.3806503 * 10-23 \mathrm{~J} / \mathrm{K})$, and $\mathrm{T}$ is the temperature.

The above mentioned equation is used to implement the PV array model in MATLAB software using the electrical specifications of the selected solar module market under the reference S-Energy (SM-245PC8) [4] polycrystalline which are shown in Table 1 at standard test condition "STC".

The STC is defined by an illuminance incident Gref equal to $1000 \mathrm{~W} / \mathrm{m} 2$ and temperature Tref equal to $25^{\circ} \mathrm{C}$. First of all, the model is simulated to plot the PV module curves for different levels of solar irradiations as shown in Fig.4 and Fig 5. The I-V graph shown in figure 4 shows that according to the temperature and irradiance, the voltage and current value also varies. Here, the current value depends on the irradiance, i.e., 
directly proportional and the voltage depends on the temperature.

Hence, the PV operating point does not stay at the maximum operating value and it varies with the environmental conditions, which in turn, reduces the power. Therefore, it is preferable to install more power generation system (PGS) than the required demand, but simultaneously, it increases the cost.

Table 1. ELCTRICAL DATA OF THE PV MODULE AT STC.

\begin{tabular}{|c|c|}
\hline Type & S-Energy \\
\hline Reference & SM-245PC8 \\
\hline Rated power (Pmax) & $245 \mathrm{~W}$ \\
\hline Voltage at Pmax (Vmp) & $30.4 \mathrm{~V}$ \\
\hline Current at Pmax (Imp) & $8.08 \mathrm{~A}$ \\
\hline Warranted minimum Pmax & $245 \mathrm{~W}$ \\
\hline Short-circuit current (Isc) & $8.63 \mathrm{~A}$ \\
\hline Open-circuit voltage (Voc) & $37.4 \mathrm{~V}$ \\
\hline $\begin{array}{c}\text { Operating module } \\
\text { temperature }\end{array}$ & $-40{ }^{\circ} \mathrm{C}$ to $+85^{\circ} \mathrm{C}$ \\
\hline $\begin{array}{c}\text { Temperature coefficient of } \\
\text { Isc }\end{array}$ & $0.052 \% /{ }^{\circ} \mathrm{C}$ \\
\hline $\begin{array}{c}\text { Temperature coefficient of } \\
\text { Voc }\end{array}$ & $-0.312 \% /{ }^{\circ} \mathrm{C}$ \\
\hline
\end{tabular}

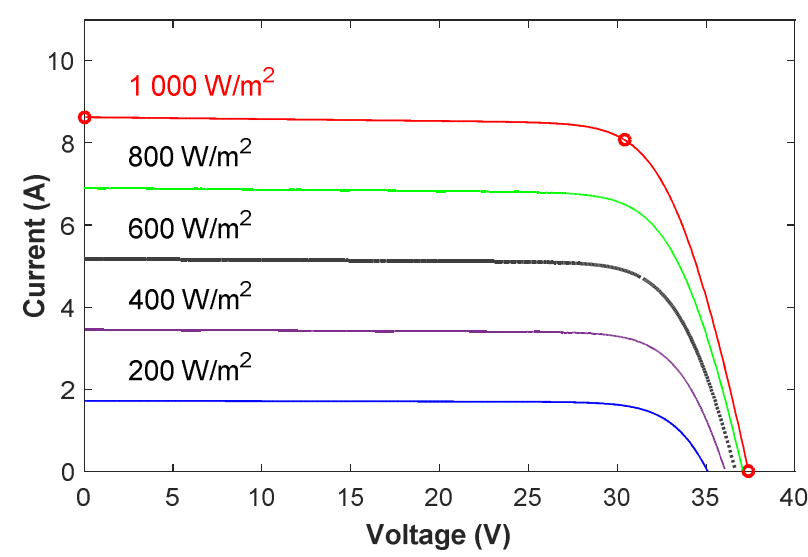

Fig. 4. Current versus voltage graph for different irradiation levels

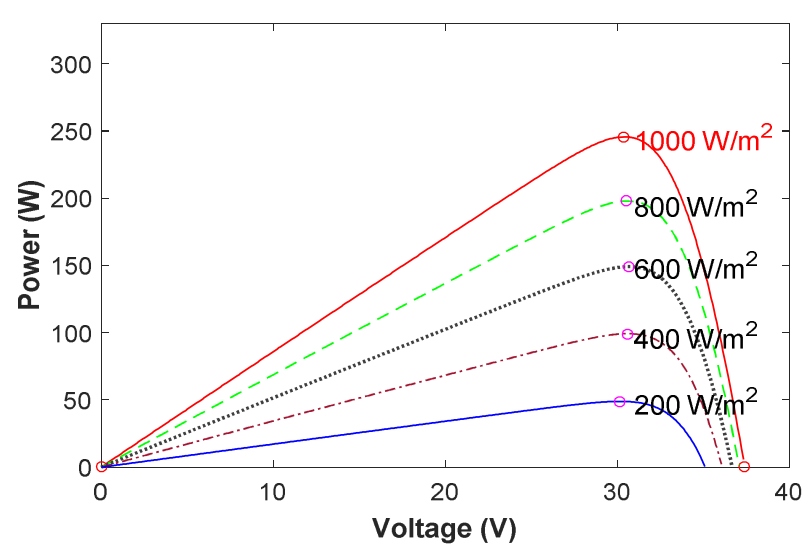

Fig. 5. Power versus voltage graph for different irradiation levels

Therefore, the dc-dc converter with an effective MPPT technique is deployed for the PV systems to modify the converter duty cycle according to the environmental conditions and there by tracks the maximum power point for all operating conditions. During uniform irradiance, the $\mathrm{P}-\mathrm{V}$ graph shows only one peak power point, which gives the corresponding maximum voltage and current. Hence, the conventional MPPT techniques would suffice to track the true MPP and is found to be reliable.

\section{DC-DC CONVERTER MODELING}

Dc-dc converters are a sizeable part of the photovoltaic conversion chain. These converters are used to adapt the input voltage of a system relative to the desired output voltage. Several types of dc-dc converter topologies of both non-isolated and isolated DC/DC converters have been addressed for photovoltaic applications in the literature.

Some of these are buck, boost, buck-boost, cuk, Single Ended Primary Inductor Converter (SEPIC) and flyback-boost converter and so on [5-7].

A boost-type converter is generally employed as the first stage instead of a transformer, to boost the wide range of voltage in the two-stage PV structure, or when requiring smaller number of modules for a given desired output voltage. This converter circuit consists of power switch (S), diode (D), inductor (L), capacitor (C), switching controller and load (R) as shown in Fig.6. This topology can be used for interface connection between the PV array and the load, not only to adapt the voltage levels but also to track the MPP of the PV array. The switch may be a MOSFET which can be turned on and off repeatedly with an operating frequency $f$ and variable duty cycle $d$. The transformation ratio of the converter is controlled by a PWM signal. The conduction of the switch and diode are complementary; the boost converter has two working modes according to the position of the switch. The first mode is when the switch is closed (ON) and the second mode takes place when the switch is open (OFF). The functioning analysis of the converter is made by applying the Kirchhoff's laws governing the operation of the system [8].

The following expression gives the relation between the output and the input voltages:

$V_{O}=\frac{1}{1-d} V$

Where Vo is the average of the load voltage vo

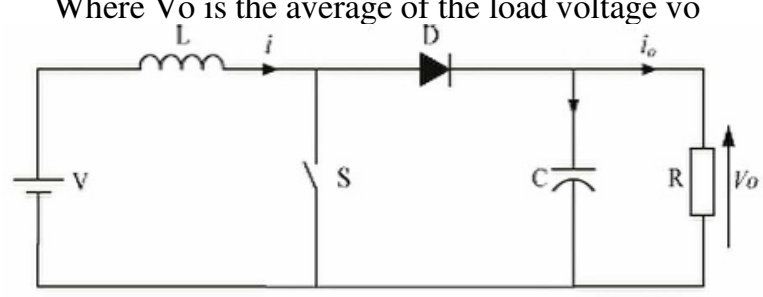

Fig. 6. Boost converter electrical circuit.

It is noted that one can control the converter output voltage by varying its input voltage or its duty cycle. The last parameter is always between 0 and 1 , then the circuit operates as a voltage booster.

By applying the principle of the power conservation between the two sides of the converter, we can deduce the relationship between currents [9-10]: 


$$
I=\frac{I}{1-d} . I_{o}
$$

Where I and Io are the input and the output average current of the converter.

\section{PERTURB AND OBSERVE (P\&O) MPPT CONTROLLER}

Conventional algorithms mainly constitute a number of variants of two basic techniques, namely, perturb and observe $(\mathrm{P} \& \mathrm{O})$ and incremental conductance. The $\mathrm{P} \& \mathrm{O}$ algorithm is an iterative approach; it needs just two sensors for sensing the current and the voltage of the PV array, and then, the output power is computed as the product of these two parameters. In this method photo-voltaic (PV) voltage and PV current are measured and resulting power P1 is calculated. Then introducing small perturbation of voltage $(\Delta V)$ or perturbation of duty-ratio $(\Delta D)$ of dc-dc converter in one direction, corresponding power P2 is calculated. Power P2 is then compared with power P1. If $\mathrm{P} 2$ is more than $\mathrm{P} 1$, then the perturbation is in correct direction, otherwise direction of the perturbation needs to be reversed. With this approach, the maximum power point is reached [11-15].

From expression (2), it shows that for a given output voltage, the input voltage of the selected converter is inversely proportional to its duty cycle. Therefore, the $\mathrm{P} \& \mathrm{O}$ can act on the duty cycle as demonstrated by the organizational chart of the algorithm of the Fig. 7 [15].

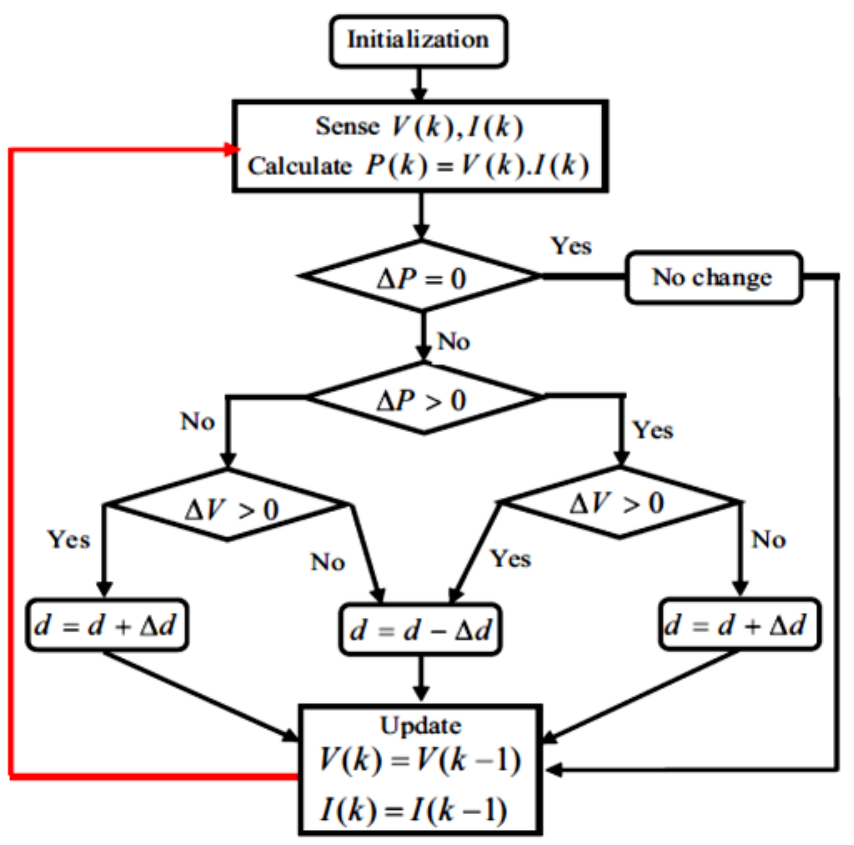

Fig. 7. Flowchart of Perturb and Observe MPPT Method

Through tuning the duty cycle of the power converter, the operating point climbs on the powervoltage characteristic to attain the peak power point, which is at the top of the curve. This technique has certain advantages such as the simple realization, being independent from solar array parameters, the high efficiency, cheap, and it requires just two grandeurs voltage and power [16-17].
However, this method has a drawback related to the continuous oscillations that occur around the MPP resulting in considerable loss of power during steady state. The principle of the proposed technique will be developed to overcome these problems. In recent years, MPPT based on soft computing methods (SCM) have attracted huge interest from research communities, due to their ability to solve the problem of the nonlinear I-V or $\mathrm{P}-\mathrm{V}$ functions.

The MPPT is formulated as an optimization problem as follows:

$$
\begin{aligned}
& \operatorname{Maximize}\left(P_{p v}(D)\right) \\
& \text { Subject to } D_{\min } \quad D \quad D_{\max }
\end{aligned}
$$

In the above, $P_{p v}$ stands for PV output power, $\mathrm{d}$ is the duty ratio of the boost converter, and $D_{\min }$ and

$D_{\max }$ are the maximum and minimum values of the duty ratio taken as $10 \%$ and $90 \%$, respectively, in this work.

\section{MPPT THROUGH ACO ALGORITHM}

Ant Colony Optimization (ACO) technique has proven to be a very powerful optimization heuristic for Combinatorial Optimization Problems [18].

This algorithm based on the biological inspiration and behavior of ants to find shortest paths from their nest to the food sources. In fact, ants are social insects that live in colonies. The ants manage to find their optimal trajectories over time, by interacting with their local environment. Initially, they search food in a random fashion, but when they have found some, they return home while depositing chemicals substances, called pheromones. These pheromones attract other ants to follow the same path, and, likewise, they turn deposit pheromones on their way back. Over time, this behavior leads to the emergence of paths, which can be shown to be near optimal. ACO is used to indicate the class of metaheuristic optimization methods that deploy these concepts in Combinatorial Optimization Problems (COPs) [19]. In the proposed methodology, the position of an ant refers to duty ratio of the dc-dc converter, and the corresponding PV output power is regarded as the pheromone content. Dedicated programs were developed in MATLAB environment for ACO-MPPT algorithm.

\section{DISCUSSION OF SIMULATION RESULTS}

The model of the proposed photovoltaic system is depicted in Fig.8. Where the PV arrays, boost converter, and the P\&O MPPT Controller have been modeled in Simulink.

The PV array consists one parallel branch; this branch consists of ten series PV modules, so the total number of modules used in the simulation is $1 \times 10=$ modules. 


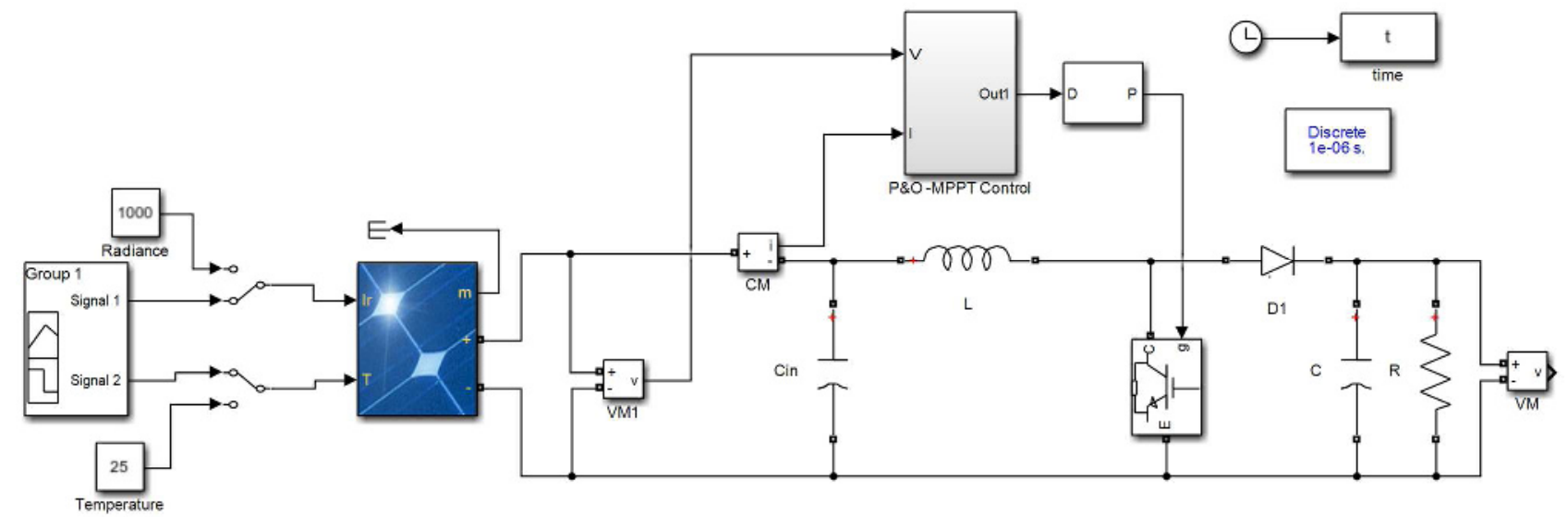

Fig. 8. The proposed MPPT system under Matlab/Simulink

The maker of these PV modules is the S-Energy (SM-245PC8). The electrical characteristics of the selected PV module are as given in Table 1. The selected solar module for this study is modeled using singlediode model to provide the current and the voltage which are introduced into the converter and the MPPT tracker simultaneously. The components of the converter are selected according to the values displayed in Table.2.

Table 2. SPECIFICATIONS OF THE BOOST CONVERTER

\begin{tabular}{|c|c|c|}
\hline Parameter & Label & Value \\
\hline $\begin{array}{c}\text { Switching } \\
\text { frequency }\end{array}$ & $\mathrm{f}$ & $10 \mathrm{KHz}$ \\
\hline Boost inductor & $\mathrm{L}$ & $0.5 \mathrm{mH}$ \\
\hline Boost capacitor & $\mathrm{C}$ & $470 \mu \mathrm{F}$ \\
\hline Input capacitor & Cin & $1000 \mu \mathrm{F}$ \\
\hline Load & $\mathrm{R}$ & $30 \Omega$ \\
\hline
\end{tabular}

To demonstrate the effectiveness of the proposed algorithm, a stringent profile for varying the solar radiation is used. This profile contains different shapes such as the step up, the step down, the ramp up and the ramp down as recommended by the European Efficiency Test, EN 50530 [20].

Test Pattern of variation in solar radiation (in Watt/sq.m.) used for simulation analysis is shown in Fig. 9.

The step change in radiation, from 800 to 600 Watt/sq.m. has been introduced at 0.5 second while ramp increase has been introduced at 1.0 second. With this profile, the proposed tracker may be tested very well under transient and steady-state conditions. The testing time was extended for 2 seconds. Meanwhile, the temperature was maintained at fixed value of $25^{\circ} \mathrm{C}$.

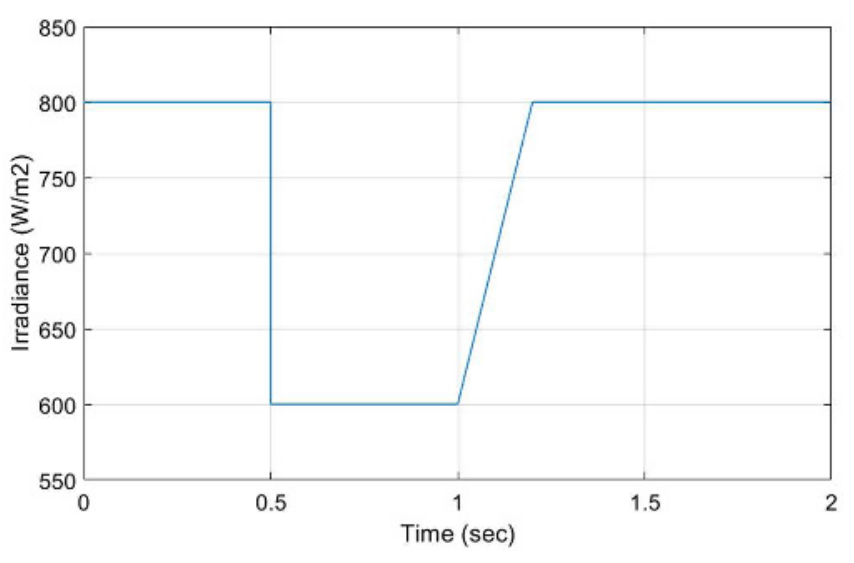

Fig. 9. Test Pattern of Solar Radiation (in W/sq.m.) used for Simulation Analysis

Simulation analysis has been carried out for different values of the duty-ratio perturbation $(\Delta \mathrm{D})$ viz. $0.001,0.01$ with manual configuration and 0.1 using the ACO algorithm. Response of input power to variations in radiation and load impedance for three different values of the duty-ratio perturbation $(\Delta \mathrm{D})$. The proposed ant-colony-based MPPT algorithm is now employed to track the optimal generated power for both the patterns and the computed results are shown in Fig.10. Fig.11 focuses on the simulated power generated between 1.644 and 1.664 seconds.

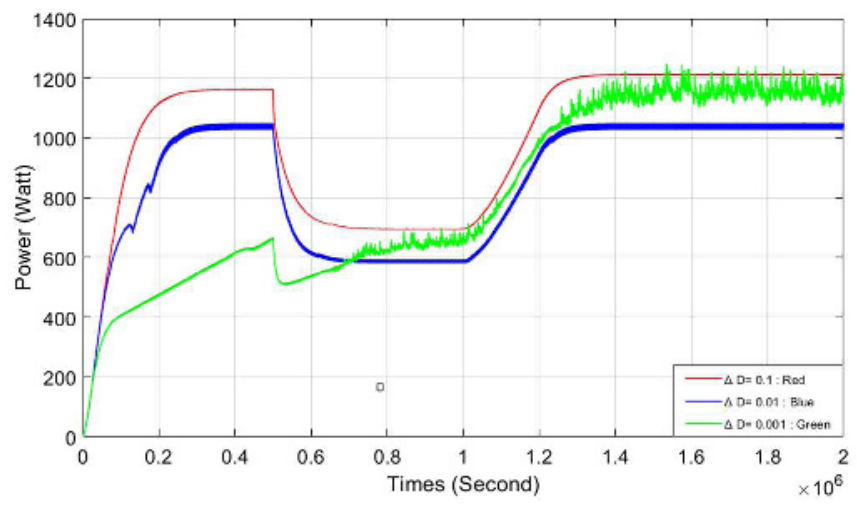

Fig. 10. Response of Out Power with $P \& O$ MPPT Controller for different $\Delta \mathrm{D}$ values 


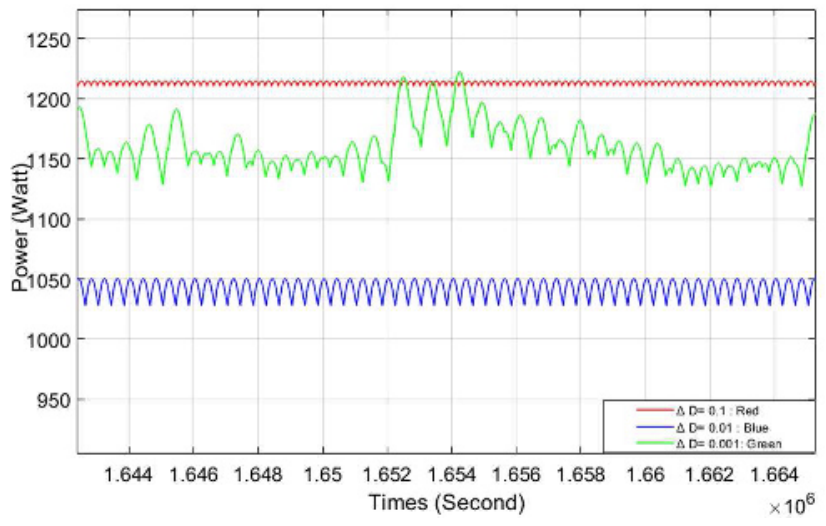

Fig. 11. Zoomed Response 1.6 second of Power with $\mathrm{P} \_\mathrm{O}$ MPPT Controller

It can be seen that the steady-state oscillations are higher in the case of $\mathrm{P} \& \mathrm{O}$ with $\Delta \mathrm{D}=0.001$, although it offers fast initial response. The $\mathrm{P} \& \mathrm{O}$ simulation results with $\Delta \mathrm{D}=0.01$ provide moderate initial response and less steady-state oscillations compared to the $\mathrm{P} \& \mathrm{O}$ using ACO method with $\triangle \mathrm{D}=0.1$. The ACO_P\&O based optimization algorithm is used to design a new MPPT controller with $\Delta \mathrm{D}=0.1$, which offers a slow start-up response with less oscillations compared to the other two methods. The tracking speed in the case of $\mathrm{P} \& \mathrm{O}$ with $\Delta \mathrm{D}=0.001$, is higher with more oscillations. The $\mathrm{P} \& \mathrm{O}$ with $\Delta \mathrm{D}=0.01$ and 0.1 offers better power point tracking and alesser oscillations. It can be observed from the simulation results that the optimum efficiency can be obtained with proper selection of perturbation size. In other words, it can be said that the size of $\Delta \mathrm{D}$ should not be very small nor very large. Simulation results clearly illustrate that the ACO-based MPPT is a promising method in assuring the peak PV output power.

\section{CONCLUSION}

In this study, a software implementation of the cost-effective P\&O MPPT technique applied to a standalone photovoltaic system was presented. The characteristic of a photovoltaic module has been detailed. A suitable power converter was selected and a stringent irradiance profile according to the European Standard Test EN 50530 was chosen to evaluate the performance of the proposed PV-MPPT system. The results show that the proposed Ant Colony Optimization ACO_P\&O_MPPT controller gives the best performances in term of convergence speed, accuracy, stability and robustness. The ACO_P\&O_MPPT controller reaches the MPP rapidly with a good accuracy and zero oscillations around the MPP at a steady state. This occurs for standard test conditions and rapid weather conditions variations. Simulation results were carried out using the MATLAB/Simulink tools.

\section{ACKNOWLEDGMENT}

The authors would like to acknowledge the support provided by the University of Sfax, Tunisia and King Faisal University, Saudi Arabia.

\section{References}

[1] M. Kamran, M. Mudassar, M. R. Fazal, M. U. Asghar, M. Bilal, R. Asghar. JKSUES 32, 7, 432-441 (2020).

[2] S. Pathy, C.Subramani, R.Sridhar, T.M.Thamizh and S. Padmanabane. Energies, 12(8), 1451 (2019).

[3] S. Titri, C. Larbes, K. Y. Toumi ,K. Benatchba. ISES 158, 490503 (2017).

[4] Data sheets available on site http://www.senergy.com/eindex.php

[5] A. Belkaid1, I. Colak, K. Kayisli. JEE 99, 839-846 (2017) Springer.

[6] K. V. G. Raghavendra, K. Zeb, A. Muthusamy , T. N. V. Krishna , S. V. S. V P Kumar , D. Kim , M. Kim , H. Cho1, and H. Kim. Electronics, 9(1), 31, (2020).

[7] N. H. Baharudin, T. M. Nizar Tunku Mansur, F. A. Hamid, R. Ali, M. I. Misrun, IJEECS 8(2), 368-374(2017).

[8] R. Reshma Gopi, S. Sreejith, RSER 94, 1-14 (2018).

[9] M. Abouelela, Cham. Green Energy and Technology (Springer), 65-105, (2019).

[10] Hashim, N., Johari, D., Ismail, N.F.N., Salam and Z. Int. JPE( Drive Syst). 9, 1038-1050. 2018

[11] K. Ishaque , Z. Salam , G. Lauss. AJ springer 119, 228-236, ( 2014).

[12] A. Neda M. Mohammad, M. Amran, M. Radzi , N. Azis , S. Shafie, M. Ammirrul and A. M. Zainuri. Appl. Sci., 10, 3912 (2020).

[13] K. Sundareswaran, V. Vigneshkumar, P. Sankar, S. P. Simon, P. S. R. Nayak, and S. Palani, IEEE TRANSACTIONS ON INDUSTRIAL INFORMATICS, 12, 1, (2016).

[14] Belkaid, A.; Colak, I.; Kayisli, K. Electr. Eng. 99, 839-846, (2017)

[15] M. S. Ngan, C. W. Tan In: IEEE Applied Power Electronics Colloquium (IAPEC), pp 22-27. (2011)

[16] J. J.-Air and al. Appl Energy 124, 309-324. (2014

[17] El K. Ahmad, Abd R. Nasrudin, S. Jeyraj, Na. U. Mohammad. IET Power Electron 6(6):1111-1121(2013). Springer Electrical Engineering 103, 1335-1345 (2021).

[18] Y. Dhieb, M. Yaich, A. Guermazi, and M. Ghariani, JES 15(1), 133-141, (2019).

[19] Ishaque K, Salam Z, Lauss G. Appl Energy 119:228-236. (2014). 